Cuadernos de Lingüística Hispánica nº 23

ISSN 0121-053X • ISSN en línea 2346-1829

Enero-Junio 2014, pp. 103-118

\title{
Análisis textual de la película Hombre mirando al sudeste*
}

LUCÍA BUSTAM ANTE VÉLEZ**

lucia.bustamante@uptc.edu.co

Recepción: 27 de septiembre de 2013

Aprobación: 8 de noviembre de 2013

* ${ }^{-}$Este es un artículo de investigación científica derivado del seminario de Pragmática del Doctorado en Lenguaje y Cultura de la Universidad Pedagógica y Tecnológica de Colombia, Uptc, orientado por el doctor Jesús González Requena en febrero de 2012.

** Doctoranda en Lenguaje y Cultura de la Universidad pedagógica y Tecnológica de Colombia, comunicadora Social-Periodista; especialista en Didáctica Universitaria; magíster en Educación, Universidad de Antioquia, Colombia; integrante del Grupo de investigación Corporación "Si Mañana Despierto" para la Creación e Investigación de la Literatura y las Artes. Docente Escuela de Idiomas de la Universidad Pedagógica y Tecnológica de Colombia. 


\section{Resumen}

En este artículo, mediante la técnica del deletreo, se hace un análisis textual de la película Honbre mirandb al sudeste, del cineasta argentino Eliseo Subiela. Para este fin, se seleccionaron algunos fragmentos cuyo tema central es la religión, específicamente el proceso de anunciación, apoteosis, sentencia y muerte de Rantés, en conexión con el relato bíblico de Jesucristo, propio del cristianismo. Finalmente, se establecen algunos puentes con la teoría psicoanalítica de Freud.

Palabras clave: pragmática, análisis textual, lenguaje cinematográfico, religión, psicoanálisis.

\section{Textual analysis of the movie Man facing southeast}

\section{Abstract}

This article develops an interpretation of the movie "Man facing southeast" [originally "Hombre mirando al sudeste"] by Argentinean filmmaker Eliseo Subiela. In order to achieve this, specific fragments were selected. The main topic in these fragments is religion, especially the process of annunciation, apotheosis, sentence and death of Rantés, connected to the biblical story of Jesus Christ which is characteristic of Christianity. Finally, a connection is established with Freud's psychoanalytical theory.

Key words: Pragmatics, textual analysis, cinematographic language, religion, psychoanalysis. 


\section{A nalyse textuelledu film homme regardant versle sud-ouest}

\section{Résumé}

D ans cet article, á travers la technique d'épeler, on fait une analyse textuelle du film Homme regardant vers le sud-auest, du cinéaste argentin Eliseo Subiela. A cet effet, on a sélectionné quelques extraits dont le sujet principal est la religion, spécifiquement le moment de l'annonciation, l'apothéose, sentence et mort de Rantés, en connexion avec le discours biblique de Jésus-Christ, propre du christianisme. Finalement, on établit quelques ponts avec la théorie psychanalytique de Freud.

M ots clés: pragmatique, analyse textuelle, langage cinématographique, religion, psychanalyse.

\section{A nálisetextual do filmeH omem olhando ao sudeste}

\section{Resumo}

0 artigo por meio da técnica de silabação faz uma analise textual do filme Homem dhandb ao sudeste, do cineasta argentino Eliseo Subieta. Para obter este fim, selecionaram-se alguns fragmentos cujo tema central é a religião, especificamente o processo de anunciação, apoteoses, sentença e morte de Rantés, em conexão com o relato bíblico de Jesus Cristo, próprio do Cristianismo. Finalmente, se estabelecem algumas pontes com a teoria psicanalítica de Freud.

Palavras chave: pragmática, analise textual, linguagem cinematográfica, religião, psicanálises. 


\section{Introducción}

El propósito del artículo es analizar la película Honbremirandb al sudeste, no desde la historia que propone, sino desde su propia materialidad. Lo anterior exige que se analice pragmáticamente, plano a plano, cada una de las secuencias, en un intento por encontrar la relación existente entre estas con otros elementos en presencia y en ausencia; esto es, deletrear, desenmascarar, desentrañar los procesos de significación presentes en una obra, más allá de las palabras y de las imágenes (G onzález Requena, 1996).

De acuerdo con lo anterior, procedo a realizar el análisis de aquellos aspectos que llamaron más mi atención, esto es, los fragmentos que tienen relación con el proceso de anunciación, apoteosis, sentencia y muerte de Rantés, en conexión con el relato bíblico de Jesucristo, propio del cristianismo. Al finalizar establezco algunos puentes con la teoría psicoanalítica de Freud, dado que la película así lo amerita.

\section{Ficha videográfica}

El título original de la película es Honbre mrandb al sudeste la cual fue estrenada en 1986 en Estudios Cinequanon; su autoría y dirección pertenecen al argentino Eliseo Subiela. Tiene una duración de aproximadamente 100 minutos y está clasificada en el género de ficción-drama. El reparto es el siguiente: Lorenzo Q uinteros (Dr. Julio D enis), Hugo Soto (Rantés), Inés Vernengo (Beatriz Dick), Cristina Scaramuzza (enfermera), Tomás Voth (Joven suicida), David Edery (D irector del hospital), Rúbens Correa (D r. Prieto).

A manera de síntesis, el film trata de un hombre llamado Rantés, quien ingresa una mañana a una clínica psiquiátrica y asegura provenir de otro mundo en una nave extraterrestre con la intención de investigar el cerebro y poder entender, según dice, la estupidez humana. El doctor Julio D enis al inicio no le presta mucha atención y piensa que es simplemente un convicto que en cualquier 
momento se va. Sin embargo, el paciente decide quedarse, y a lo largo de las sesiones de tratamiento demuestra habilidades excepcionales que intrigan al médico. Las teorías, razonamientos y actitudes de Rantés ponen a pensar al psiquiatra, a replantearse su vida y profesión y a cuestionar los paradójicos comportamientos del paciente.

\section{G énero discursivo y situación de comunicación}

El film cinematográfico, como todo episodio de enunciación, es un acto de decir en un contexto determinado. Bajo esta consideración, se procede a determinar el género discursivo, la situación de comunicación y, consecuentemente, al análisis religioso.

Según la clasificación hecha por Bajtín (1999), el género discursivo 0 contrato social del habla en el film es secundario. En este acto enunciativo interviene un conjunto de elementos que determina la situación comunicativa, esto es, la forma que toma la enunciación.

Hombremirandbal sudestees un texto narrativo de ficción y drama, el cual tuvo lugar en Buenos Aires, Argentina, país de origen del director y poeta Eliseo Subiela, quien además es el autor del guión. Podría decirse que el film es plurisignificativo, en la medida en que el interlocutor (lector real), como un espectador crítico, reflexivo y creativo, puede vislumbrar varios propósitos que pueden o no corresponder con la visión inicial del autor-director: narrar la manera insensible y fría en que son tratados los pacientes en un hospital psiquiátrico, ante la falta de afecto, comprensión e interés por la persona. De otro lado, hacer una crítica a la cultura de la época, agobiada por el sufrimiento de los seres humanos ante las injusticias, representadas en las instituciones sociales como la religión, la familia, el Estado, el sistema carcelario, la educación, la salud, etc. Y, en tercer lugar, poner en entredicho el carácter racional e inhumano de la ciencia, incapaz de aceptar razones por fuera de su propia lógica.

Los temas que resalta el autor son el poder, el hambre, la religión, la insensibilidad de la sociedad, la muerte, la racionalidad de la ciencia, la locura, como aspectos irracionales del ser humano; la exaltación de la música, el amor, la comprensión, la amistad, como aspectos enaltecedores de la razón. Lo curioso y cautivante para el receptor analítico de la película consiste en los permanentes entrecruzamientos entre los aspectos racionales e irracionales. 


\section{El aspecto religioso}

En primer lugar, nótese cómo algunas imágenes a lo largo del texto fílmico nos introducen en el tema religioso. Es importante para el autor-productor crear una atmósfera que contribuya a fijar el aspecto religioso cristiano en el discurso que tiene lugar en la clínica.

En primer lugar se enfoca la iglesia y, dentro de esta, vitrales con motivos sacros; también vemosla cruz, símbolo del cristianismo, con insistente frecuencia en varias de las escenas en las que tienen lugar los diálogos de los personajes.

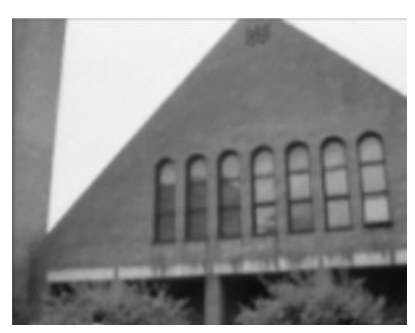

Imagen 1

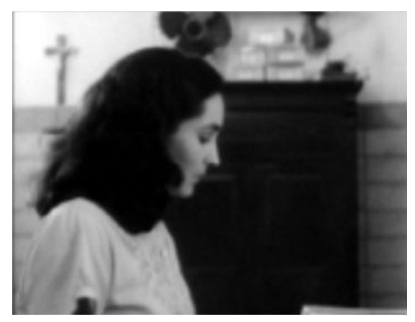

Imagen 4

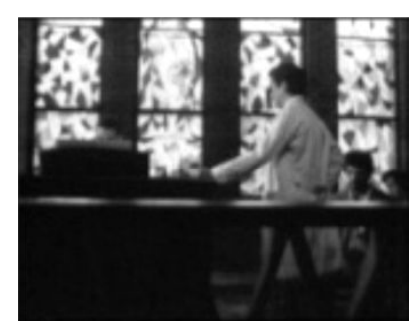

Imagen 2

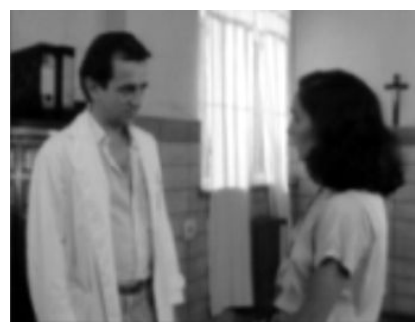

Imagen 5

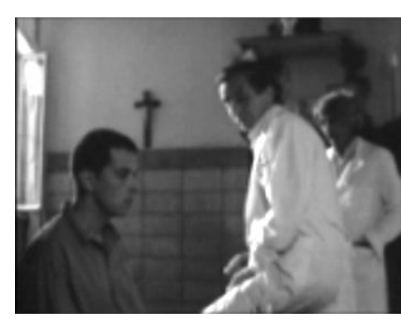

Imagen 3

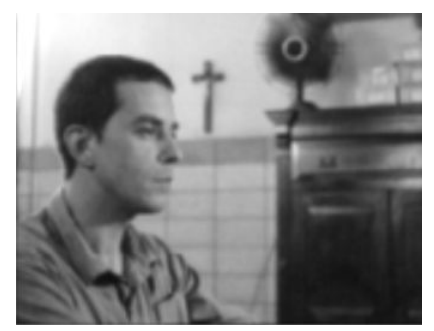

Imagen 6

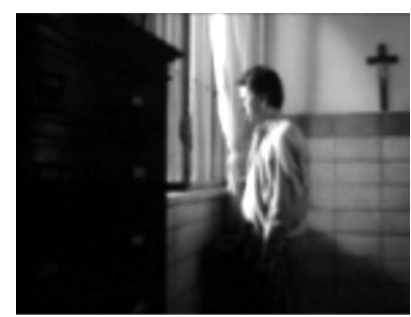

Imagen 7

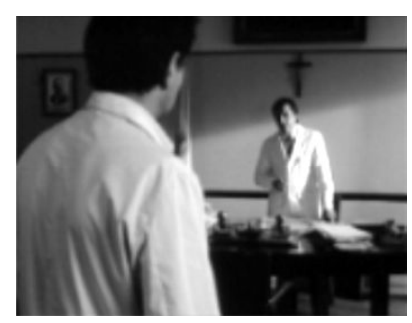

Imagen 8

La imagen 1 corresponde al fragmento en el cual el doctor D enis se dirige a la Iglesia a conocer al nuevo paciente, en respuesta al anuncio que le hiciera uno de los enfermos en cama, cuando el doctor pregunta: “¿cuál es?”: "está en la 
iglesia doctor, es un hombre muy bueno y viene de muy lejos". El doctor camina hacia la Iglesia mientras la cámara lo sigue y hace un cabeceo oblicuo en contrapicado hacia el símbolo religioso colocado en el vértice superior de la iglesia, deteniéndose por unos segundos en este, ubicando al espectador en el lugar al que va a entrar el doctor.

La imagen 2, en un plano entero, deja ver, en el segundo piso de la iglesia, los vitrales con motivos religiosos, a medida que el doctor se dirige hacia quien toca el piano. También es posible ver, mientras el doctor sube las escaleras, los cuadros de imágenes religiosas en las paredes. La música de piano contribuye a crear dicha atmósfera.

En la imagen 3 vemos a Rantés cuando es interrogado por dos doctores del hospital, en un plano americano, donde se puede apreciar la cruz en la pared al fondo del salón.

De la misma manera, en las imágenes 4 y 5 , observamos la cruz al fondo mientras Beatriz y el doctor D enis dialogan, enfocados en distintos planos y ángulos.

La imagen 6 corresponde al diálogo sostenido entre el doctor D enis y Rantés, en el cual el doctor interroga al paciente sobre su actitud de darle su abrigo al paciente suicida. Al fondo se observa la cruz. Esta misma escena se desarrolla en el capítulo 8, imagen 9, como se verá más adelante.

Igualmente, el director del film quiere llamar la atención del espectador sobre la cruz en la pared, al encuadrarla en las escenas que tienen lugar en el consultorio del doctor D enis, mientras observa a Rantés por la ventana (imagen 7), así como en la dirección de la clínica, en la conversación entre el director y el médico (imagen 8).

\subsection{Las pistas de C risto}

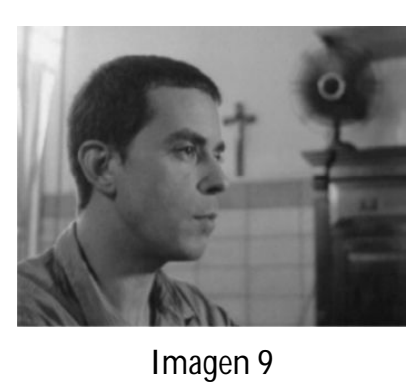

Nótese el ritmo narrativo de la acción en el encuadre de la imagen 9, correspondiente a la escena en que el doctor Denis interroga a Rantés sobre el significado de la caja de recortes encontrada debajo de su cama, cómo la cámara, en un plano corto, enfoca la cruz en la escena, en tanto el protagonista le habla al doctor de su misión en la tierra. 
Mientras hablan, la cámara enfoca al doctor en un plano medio corto, y luego, en un travelling lateral de derecha a izquierda, se dirige hacia el paciente; en el recorrido se enfoca, insistentemente, la cruz al fondo, en la pared; lentamentela cámara mediante un zoom enfoca a Rantés hasta un plano de busto y persiste por breves segundos en enfocar la cruz. Como se dijo antes, esta misma escena se repite en la imagen 6.

En el desarrollo de esta secuencia, el cineasta nos brinda abundantes pistas sobre el rol que juega la cruz en la película, mientras el psiquiatra descubre el verdadero papel desempeñado por el paciente en su historia delirante de extraterrestres: dolor, sufrimiento y rescate, analogías con la figura de Jesucristo.

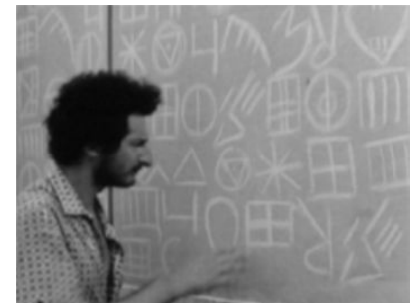

Imagen 10

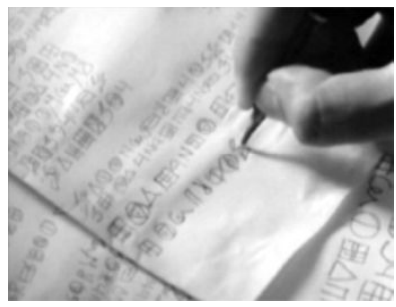

Imagen 11

La utilización de los símbolos y figuras en la película se asemeja a la revelación de lavictoriafinal y decisiva de $D$ ios, por medio de Cristo, sobre los poderes malignos, por lo que los creyentes debían permanecer firmes y fieles en medio del sufrimiento y la persecución. En el libro del Apocalipsis del Nuevo Testamento se hace alusión a una serie de revelaciones y visiones con un gran número de símbolos y un lenguaje alegórico que los lectores cristianos de su tiempo entendían. Nótese en la película cómo el protagonista escribe en un lenguaje simbólico todas sus observaciones (imágenes 10y 11), y cuando es sorprendido por el doctor D enis en el laboratorio de patología, las esconde. Al respecto, llama la atención el siguiente versículo del Apocalipsis: "[... ] y oí detrás de mí una fuerte voz, como un toque de trompeta, que me decía: escribe en un libro lo que ves, y mándalo a las siete iglesias de la provincia de Asia: a Efeso, Esmirna, Pérgamo, Tiatira, Sardis, Filadelfia y Laodicea" (1, 1011). La actitud de Rantés entra en diálogo con el versículo citado.

\subsection{Anunciación, apoteosis, sentenciay muertede Rantés}

El Evangelio según San Juan (3, 31-32) narra la llegada de Jesús desde el cielo, para hacer la voluntad de Dios, pero muy pocos creyeron lo que dijo; de la misma manera, Rantés afirma venir de otro planeta a hacer la voluntad de un ser superior, 
por lo que es considerado un loco. La analogía es evidente: dos seres que se autoproclaman como enviados de una trascendencia superior para redimir a la humanidad. El resultado es la polarización de los otros seres: Jesús y Rantés son considerados genios o dementes.

En una de las escenas el doctor D enis pregunta a Rantés el significado de los recortes en la caja y este responde que significan los crímenes que se cometen cotidianamente en el mundo, además de recriminarle con la siguiente sentencia: "Si Dios está en cada uno de ustedes, están asesinando a D ios todos los días". Rantés afirma ser uno de los enviados a preparar el rescate de las víctimas, de los que no tienen cabida en el mundo a causa del espanto, el horror y la desesperanza. Ante estas aseveraciones la respuesta del médico no se hace esperar: "Rantés [... ] creo que cometió un error al asumir su papel, no debió haberme dicho que eraun habitante de otro planeta, debió haberme dicho que era Cristo".

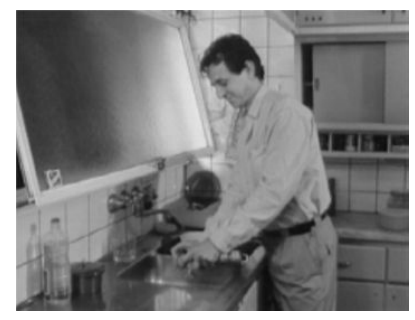

Imagen 12

Las siguientes escenas tienen lugar en la residencia del doctor D enis, quien en el papel de narrador intradiegético, realiza un monólogo interior, en el cual medita y sonríe ante sus descabellados pensamientos (imagen 12). Piensa en la historia de Cristo narrada por Rantés y sale a la luz el punto de vista del personaje: incredulidad y escepticismo: "La idea de una invasión de cristos me causaba gracia, que Dios me perdone, pero era una idea tan disparatada, que me causaba gracia. La otra, la antigua, la oficial, de un solo Cristo también me pareció siempre un disparate, pero nunca me causó gracia”. La música del saxo de fondo contribuye a darle un matiz dramático a la reflexión sobre la historia de Cristo recreada por el psiquiatra.

El anuncio de Rantés de su llegada a la tierra como una personificación de Cristo sumerge al médico en un mar de confusiones y contradicciones. "Pensaba si todo fuera cierto, por qué mientras aquel Cristo era un ser social, mientras aquel tenía una parte política, este en cambio se aislaba, buscando el más total de los anonimatos. Aunque si aquella vez no había ido del todo bien, no era un disparate pensar que esta vez hubieran decidido usar otra táctica. Diosmío, seguramente Rantés tenía razón en cuanto a que los psiquiatras nos tiramos para atrás con la silla para no contagiarnos. En todo caso, con él, yo había cometido la imprudencia de no hacerlo".

A medidaque el psiquiatra se familiarizabay adentraba en el tema, conversando con Rantés, sus reflexiones y dudas iban en aumento: “[... ] Providencialmente en él 
apareció la furia. Si intentaba ser un Cristo cibernético, la furia lo iría semejando poco a poco al otro Cristo, al antiguo [... ] porque en la medida en que Rantés se acercara a Cristo, su final no sería muy distinto". El doctor no era desconocedor del desenlace que tendría la historia.

D enis comienza a pensar que era preferible que Rantés desapareciera de su mundo: "Aunque en algún lugar de la historia del universo, si todo esto era cierto yo me convirtiera en el Pilatos de las galaxias. En ese caso yo prefería como le debe haber pasado a muchos de los romanos, arriesgarme a una resurrección y no tenerlo ahí delante diciendo las cosas que decía”. Esta escena se ambienta bellamente con la interpretación del saxo por parte del doctor.

Los momentos gloriosos de Rantés comienzan desde su llegada al hospital, cuando empieza a dar señales del papel que desempeñaría en la narración: "está en la iglesia, doctor; es un hombre muy bueno y viene de muy lejos", dice uno de los pacientes (imagen 13); se ubica en el jardín en posición de transe (imagen 14); distrae al vigilante de la clínica arrojando con su mente la radio al piso (imagen 15); mueve la comida en el restaurante hacia la familia de indigentes y destruye los vasos para distraer al dueño mientras les hace señas para que escapen (imagen 16). Esta escena es acompañada por música religiosa en latín, en off, lo cual le añade dramatismo y misterio. De manera similar, Jesús hizo milagros y dio pan a los hambrientos.

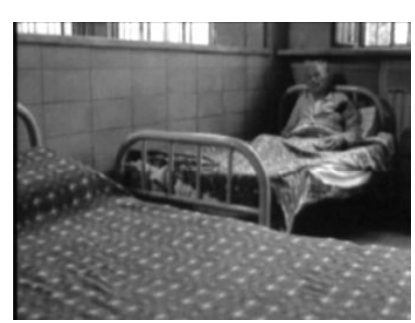

Imagen 13

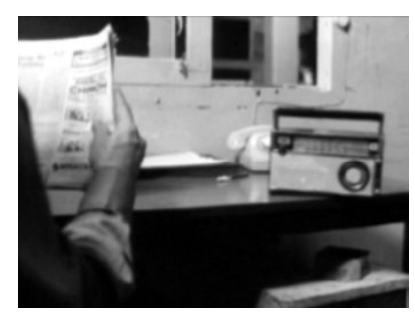

Imagen 15

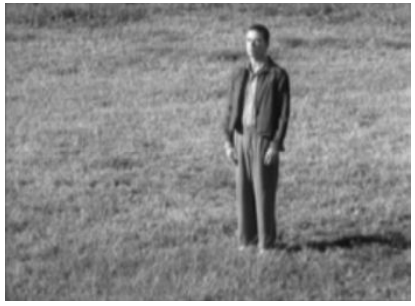

Imagen 14

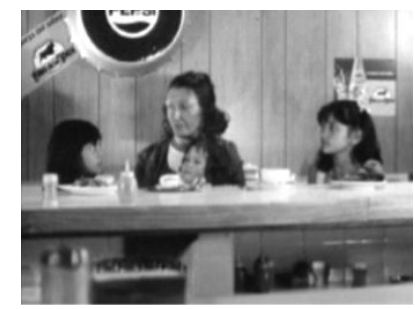

Imagen 16 
En el hospital, Rantés es un consuelo para los enfermos, quienes se convierten en sus más fervientes seguidores (imágenes 17, 18 y 19) al igual que los discípulos de Jesús, quienes lo seguían por todo Jerusalén; y así como Jesús enseñó en el templo y los judíos decían: “¿Cómo sabe este tantas cosas, sin haber estudiado? (San Juan 7, 15), Rantés sabe de todo, toca el piano en el templo de manera magistral y enseña música a los niños, asiste varios partos como si fuera un médico, como lo afirmara Beatriz.

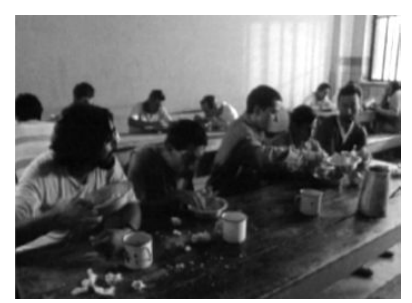

Imagen 17

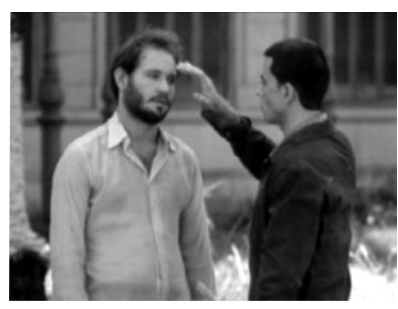

Imagen 18

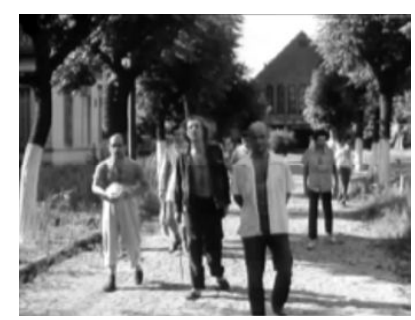

Imagen 19

Sin embargo, el momento apoteósico tiene lugar durante la celebración del concierto en el parque; allí Rantés dirigió la orquesta filarmónica e interpretó la novena sinfonía de Bethoven con gran virtuosismo, y fue vitoreado por los presentes, llenándolos de júbilo, al igual que a los pacientes de la clínica, que de forma inexplicable también estaban eufóricos. De la misma manera, Jesús fue ensalzado en la fiesta de Pascua, en la cual tuvo una entrada gloriosa a Jerusalén. La composición visual y sonora en las que el director combina simultáneamente música presencial (parque, imágenes 20, 21, 22) y no presencial (hospital, imágenes 23 y 24) constituyen momentos emotivos y expresivos de gran sensibilidad.

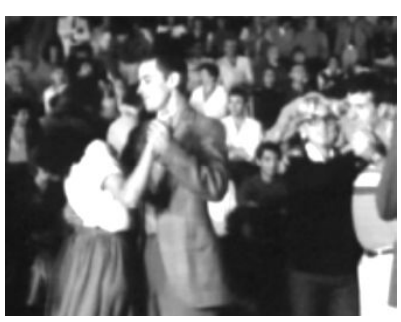

Imagen 20

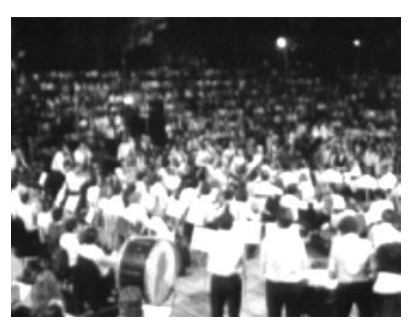

Imagen 21

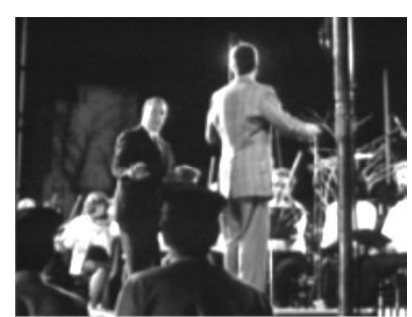

Imagen 22 


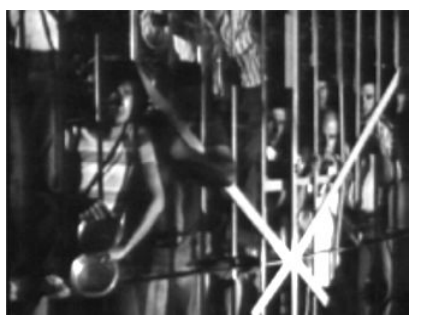

Imagen 23

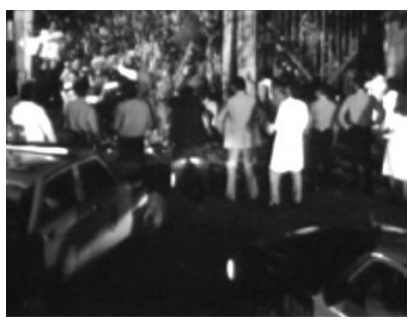

Imagen 24

Pero, así como Jesús tuvo como antagonistas a los fariseos, Rantés encontró en los médicos del centro hospitalario a los suyos, pues, los acontecimientos en el parque fueron publicados en la prensa (imagen 25) y rechazados enérgicamente por el director de la clínica, quien afirmaba que él había liderado los disturbios en el hospital la noche anterior, según le informaron los enfermos. En la mañana el doctor D enis observa a los funcionarios fúnebres retirar algunos cadáveres como consecuencia de los desórdenes (imagen 26). Sabía que la decisión que iba a tomar significaba la muerte de Rantés y también, de alguna manera, la suya, como se puede entender en sus reflexiones: "La sentencia estaba dictada y se iba a cumplir. D espués de todo en esa historia yo solo era Pilatos".

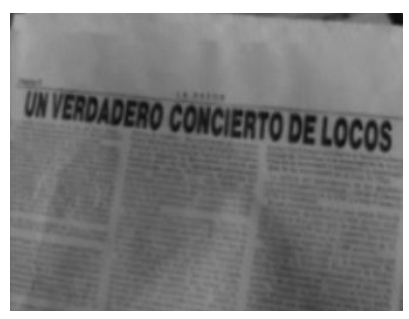

Imagen 25

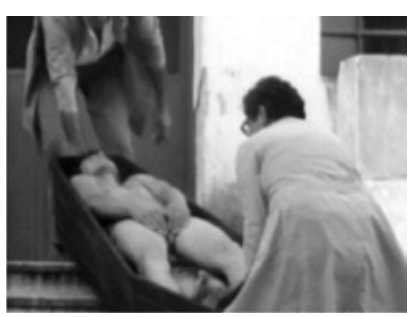

Imagen 26

En las imágenes 27 y 28 se observa al doctor D enis apesadumbrado por tener que acatar las órdenes del director del hospital de medicar a Rantés y retirarlo del laboratorio. En estas escenas, el doctor le asegura al paciente que no lo va a abandonar. El doctor sabe que este será su fin, así como lo sabe el protagonista, pues como Jesús, también acepta su destino. 


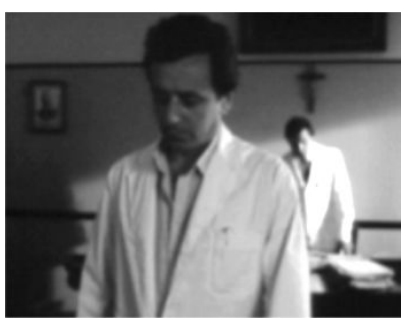

Imagen 27

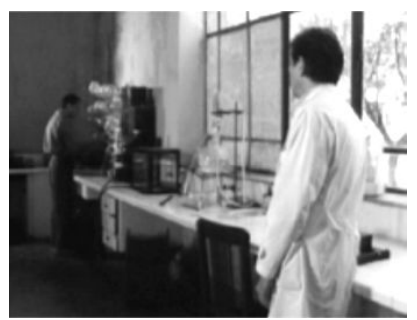

Imagen 28

Con la decisión de medicar a Rantés comienza su derrumbamiento. A partir de estas escenas, el doctor hace de narrador intradiegético. Cuando lo inyectan, Rantés acepta resignado su destino (imagen 29); su orientación hacia las transmisiones falla (imagen 30 y 35) y protesta reclamando mejor comida para los pacientes de la clínica (imagen 31 y 32).

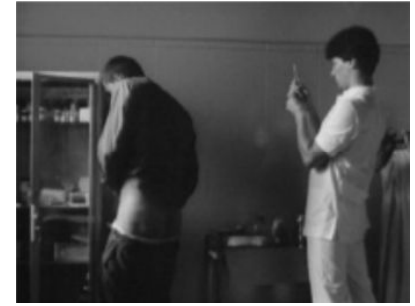

Imagen 29

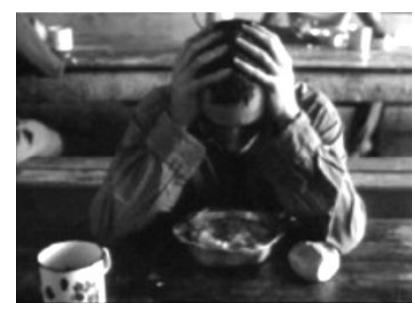

Imagen 32

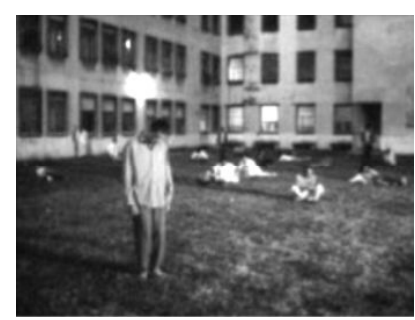

Imagen 35

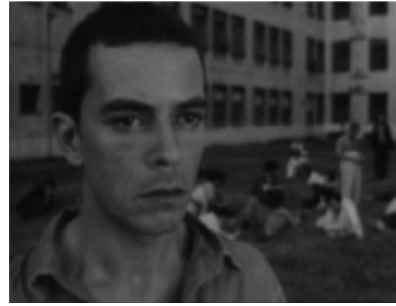

Imagen 30

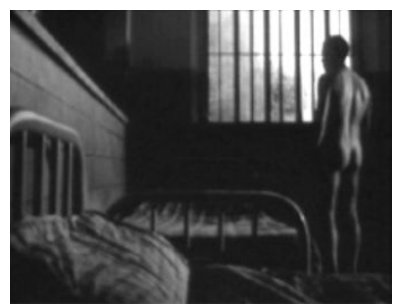

Imagen 33

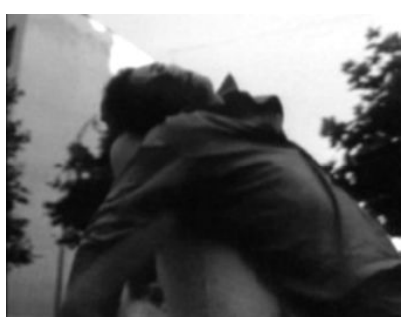

Imagen 36

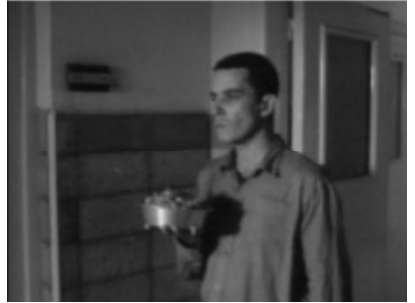

Imagen 31

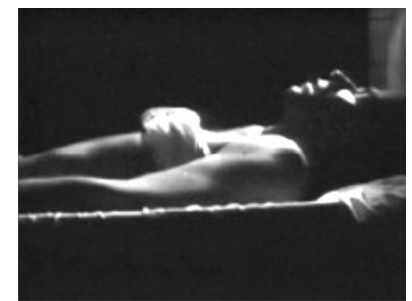

Imagen 34

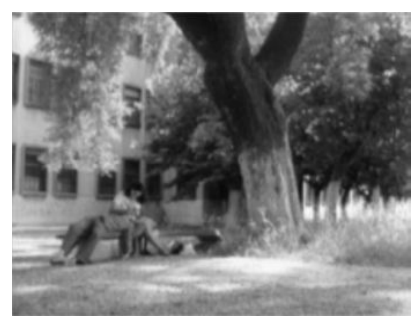

Imagen 37 


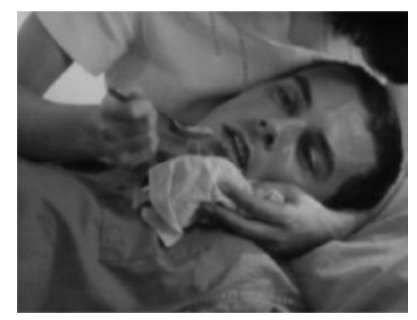

Imagen 38

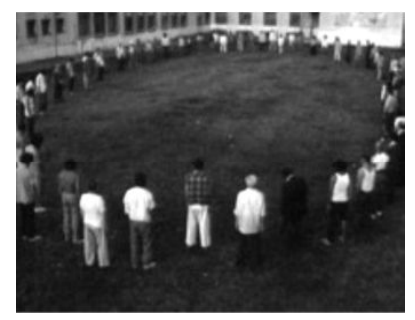

Imagen 39

La escena en la que Rantés le dice al psiquiatra: "D octor, doctor, por qué me abandona" (imagen 34) es extremadamente dolorosa, reforzada porla música fúnebre de fondo. Estas escenas recuerdan a las del relato bíblico en el momento en que Jesús anuncia su muerte y dice sentir una angustia terrible (imágenes 33, 37, 38). Igualmente, la pasión de Cristo es vivida por el protagonista en algunas escenas, por ejemplo, la imagen del paciente arrastrando a Rantés después de que este desfalleciera en el campo del hospital (imagen 36) se asemeja a la de Cristo cargando su cruz hacia el Gólgota, lugar en el que fue crucificado. La escena de Beatriz dando agua a Rantés en su agonía (imagen 37-38) se compara con la que tuvo Cristo cuando dijo: "tengo sed".

El nueve defebrero de 1985 Rantés muere de un paro cardiaco. Los enfermos no creen en su deceso y se reúnen en círculo. Dicen que se fue, pero que volverá en una nave a buscarlos y que ellos estarán ahí, esperando (imagen 39). Jesús muere para resucitar a los tres días: - "voy a estar con ustedes solamente un poco de tiempo y después regresaré al que me ha enviado" (San Juan 7, 33).

\section{Influencia del psicoanálisis}

Se percibe mucha influencia de Freud en la películay téngase en cuenta que el psicoanálisis fue una de las disciplinas que se estigmatizaron durante la dictadura militar en Argentina. Tanto Rantés como Denis reflejan una fuerte inclinación hacia la poesía y la música. Según Freud, el arte y la ciencia, máximas creaciones del hombre, son esenciales para quienes la poseen, pero a quienes les falta la religión, viene a ser un sustituto, y téngase en cuenta que Freud tampoco era muy cercano a la religión, lo cual contribuye a entender la censura al psicoanálisis, en este país, en dicho momento histórico.

En la búsqueda de la felicidad, el ser humano debe elegir entre dos caminos; uno positivo, mediante la obtención del placer, y otro negativo que lo insta a evitar el dolor. Este libre juego de elección y adaptación viene a ser perturbado por la 
religión al pretender imponer un camino único para alcanzarla. Como medidas, reduce el valor de la vida y deforma delirantemente la imagen del mundo real, mediante la intimidación de la inteligencia. Fuerza así al individuo a un infantilismo psíquico y lo hace participar en un delirio colectivo. De esa manera, la religión logra evitar a muchos seres la caída en la neurosis individual; pero hasta allí solamente llegan sus alcances (Freud, 1987).

El objeto de la vida humana es justificado en razón de un sistema religioso, por fuera de él esta no tiene sentido.

Las fuentes del sufrimiento humano, señaladas por Freud, son: la supremacía de la naturaleza, la caducidad de nuestro propio cuerpo y lainsuficiencia de nuestros métodos para regular las relaciones humanas en la familia, el Estado y la sociedad.

La película evidencia claramente una actitud frente al tercer motivo de sufrimiento: el de origen social. Rantés no comprendeni acepta la injusticia humana proveniente de las instituciones llamadas a la protección y al bienestar de todos, y se pregunta la razón por la que al individuo le resulta tan difícil ser feliz. Él mismo no es feliz, pues en su neurosis intenta eliminar 0 atenuar el dolor de quienes lo rodean.

La ausencia del sentimiento aparece en la película como una debilidad y a la vez como una fortaleza en el protagonista: "Somos seres perfectos, excepto por una cosa: no podemos sentir", declara Rantés al doctor. En esta oración entendemos cómo el bien deriva de esta condición, la cual se presenta como una pantalla que infortunadamente es traspasada por algunos, lo que los vuelve vulnerables al sufrimiento: "los más interesantes preventivos del sufrimiento son los que tratan de influir sobre nuestro propio organismo, pues en últimainstanciatodo sufrimiento no es más que una sensación; sólo existe en tanto lo sentimos, y únicamente lo sentimos en virtud de ciertas disposiciones de nuestro organismo" (Freud, 1987, p. 14).

La realidad se presenta para Rantés como fuente de sufrimiento, por lo cual se construye un nuevo mundo más cercano a sus deseos, empeñado en transformarlo y eliminar los rasgos más intolerables como la miseria y la violencia. Respecto a ello, Freud (1987) afirma: "Q uien en desesperada rebeldía adopte este camino hacia la felicidad, generalmente no llegará muy lejos, pues la realidad es la más fuerte. Se convertirá en un loco a quien pocos ayudarán en la realización de sus delirios". Y añade: "también las religiones de la Humanidad deben ser consideradas como semejantes delirios colectivos. D esde luego, ninguno de los que comparten el delirio puede reconocerlo jamás como tal” (p. 17). 
La estrategia de Rantés al llegar al hospital es en procura de un seguro de felicidad y una protección contra el dolor, por medio de una transformación delirante de la realidad. Lo que vemos en Rantés es una fuga a la neurosis, como lo expresa Freud (1987), al señalar que quien vea fracasar en edad madura sus esfuerzos por alcanzar la felicidad, aún hallará consuelo en el placer de la intoxicación crónica 0 emprenderá una desesperada tentativa de rebelión como es la psicosis (p. 20).

Los enfermos mentales de la película ponen como antídoto contrala ausencia de sentimiento el amor y las manifestaciones estéticas como la música. Freud dice que la belleza y el amor son métodos utilizados por el ser humano para conquistar la felicidad y alejar el sufrimiento. La música se presenta en el film como una satisfacción sustituta, una ilusión frente a la realidad, eficaz psíquicamente, gracias al papel que la imaginación mantiene en la vida anímica.

\section{A maneradeconclusión}

En Freud parece radicar la razón de Rantés de entender la estupidez humana y sus esfuerzos por penetrar el cerebro en procura de comprender por qué obtener la felicidad mediante el placer no es posible. Para soportar su existencia, Rantés hace uso de lenitivos, referidos por Freud, como distracciones poderosas que empequeñecen nuestra miseria; satisfacciones sustitutas que la minimizan y narcóticos que nos insensibilizan ante ella.

Los narcóticos influyen sobre nuestros órganos y modifican su quimismo, por eso Rantés se niega a consumir la medicación del hospital. El trabajo en el laboratorio de patología se vuelve una necesidad apremiante para Rantés: "[... ] nada lo distrae como esto", dice Beatriz al doctor D enis. Freud sostiene que algunos de estos remedios son indispensables para soportar la vida con sus excesivos sufrimientosy decepciones y que también la actividad científica es una diversión semejante.

\section{R eferencias bibliográficas}

Bajtín, M. (1999). Estética dela đæacón vedbal. México: Siglo XXI Editores. Celam (1979). La Biblia México: Consejo Episcopal Latinoamericano.

Freud, S. (1987). El malestar enla altura yctros ensayos Madrid: E ditorial Alianza. González Requena, J. (1996). “El texto: tres registros y una dimensión”. En: Tramay Fonda № 1. pp. 3-32. Madrid: Asociación Cultural Trama. 